\title{
Mapping out the structural changes of natural and pretreated plant cell wall surfaces by atomic force microscopy single molecular recognition imaging
}

Mengmeng Zhang ${ }^{1}$, Guojun Chen ${ }^{1,2}$, Rajeev Kumar ${ }^{3}$ and Bingqian $\mathrm{Xu}^{{ }^{*}}$

\begin{abstract}
Background: Enzymatic hydrolysis of lignocellulosic biomass (mainly plant cell walls) is a critical process for biofuel production. This process is greatly hindered by the natural complexity of plant cell walls and limited accessibility of surface cellulose by enzymes. Little is known about the plant cell wall structural and molecular level component changes after pretreatments, especially on the outer surface. Therefore, a more profound understanding of surface cellulose distributions before and after pretreatments at single-molecule level is in great need. In this study, we determined the structural changes, specifically on crystalline cellulose, of natural, dilute sulfuric acid pretreated and delignified cell wall surfaces of poplar, switchgrass, and corn stover using single molecular atomic force microscopy (AFM) recognition imaging.
\end{abstract}

Results: The AFM tip was first functionalized by a family 3 carbohydrate-binding module (CBM3a) (Clostridium thermocellum Scaffoldin) which specifically recognizes crystalline cellulose by selectively binding to it. The surface structural changes were studied at single molecule level based on the recognition area percentage (RAP) of exposed crystalline cellulose over the imaged cell wall surface. Our results show that the cell wall surface crystalline cellulose coverage increased from $17-20 \%$ to $18-40 \%$ after dilute acid pretreatment at $135^{\circ} \mathrm{C}$ under different acid concentrations and reached to $40-70 \%$ after delignification. Pretreated with $0.5 \%$ sulfuric acid, the crystalline cellulose surface distributions of $23 \%$ on poplar, $28 \%$ on switchgrass and, $38 \%$ on corn stover were determined as an optimized result. Corn stover cell walls also show less recalcitrance due to more effective pretreatments and delignification compared to poplar and switchgrass.

Conclusions: The dilute acid pretreatment can effectively increase the cellulose accessibility on plant cell wall surfaces. The optimal acid concentration was determined to be $0.5 \%$ acid at $135^{\circ} \mathrm{C}$, especially for corn stover. This study provides a better understanding of surface structural changes after pretreatment such as lignin relocation, re-precipitation, and crystalline cellulose distribution, and can lead to potential improvements of biomass pretreatment.

Keywords: Plant cell wall, Dilute acid pretreatment (DAP), Surface structural changes, Carbohydrate-binding module, AFM recognition imaging, Recognition area percentage (RAP)

\footnotetext{
* Correspondence: bxu@engr.uga.edu

'Single Molecule Study Laboratory, College of Engineering and Nanoscale Science and Engineering Center, University of Georgia, Athens, GA 30602, USA

Full list of author information is available at the end of the article
} 


\section{Background}

The fossil fuel scarcity has become a serious problem and exploring alternative energy sources has drawn increasing attentions from both academia and industry. To find renewable and sustainable replacements of crude oil, the lignocellulosic biomass (such as poplar, switchgrass, and corn stover), has been considered as one of the primary feedstocks with potentials of high efficiency and low cost [1-4]. Enzymatic hydrolysis of plant cell walls has overwhelming advantages over chemical treatments of lower energy consumption, less hazardous byproducts, nearly theoretical yields, etc. $[3,5]$. As the most promising strategy, direct hydrolysis of plant cell wall cellulose (the major component of plant cell walls) by enzymes, however, is greatly hindered due to the natural complexity of the plant cell walls $[1,6,7]$. The cellulose microfibrils are embedded in the cross-linked hemicellulose and lignin matrix, which reduces the direct accessibility of enzyme binding to them [7-9]. To overcome this recalcitrance, several pretreatments have been developed to enhance the cellulose degradability [10-12].

The essential role of pretreatment is to physically and/or chemically disassemble the protective carbohydrate-lignin complex, disrupt the crystalline structure of cellulose and more importantly, increase the surface accessibility of plant cell wall carbohydrates $[11,13]$. Some extensively studied pretreatment technologies include steam explosion [14], ammonia fiber expansion (AFEX) [15], ammonia recycled percolation (ARP) [16], lime [17], dilute acid pretreatment [18], etc. Each pretreatment has specific advantages and disadvantages in hemicellulose degradation and lignin removal, but all have been proven to change the plant cell wall structure [10]. Dilute acid pretreatment (DAP), especially with dilute sulfuric acid, has received extensive attentions for several decades in fuel production. Its major objective is to extensively solubilize hemicellulose (over $80 \%$ of the natural content) and disrupt the carbohydrate-lignin linkage to enhance the enzymatic digestibility of cellulose $[11,19,20]$. Although little lignin is removed, the disruption and re-localization of lignin have been clearly verified which can slightly increase the exposed surface area of cellulose for hydrolysis [21-23].

Enzymatic hydrolysis usually proceeds from outer surface of the plant cell wall. Extensive distribution of hydrolysable components (i.e., cellulose and hemicellulose) on the surface therefore can facilitate the cell wallenzyme interactions and improve the hydrolysis efficiency. Consequently, an in-depth understanding of structural changes of pretreated cell wall surface, especially at single molecule level, can provide a fundamental insight of cell wall ultrastructure for pretreatment improvement. Some frequently used techniques to characterize the plant cell walls are X-ray diffraction (XRD), nuclear magnetic resonance (NMR), infrared spectroscopy (IR), high performance liquid chromatography (HPLC) [10,24-26], etc. These techniques are usually used as a combination to identify the structural and component changes of the plant cell walls. However, the plant cell wall structure following pretreatments is completely or partially destroyed and the chemical changes determined by bulk chemical analysis do not necessarily reflect the changes on the surface. Alternatively, scanning electron microscopy (SEM), transmission electron microscopy (TEM), and atomic force microscopy (AFM) can provide surface morphology information but do not provide information on chemical composition $[25,27,28]$. Fluorescence microscopy [29] and time-of-flight secondary ion mass spectrometry (ToF-SIMS) [30] are also applied in cell wall surface analysis, but the accuracy of component distributions on surface is unsatisfactory due to the limited mapping resolution.

AFM recognition imaging by functionalized AFM tips has been widely used to map the substrate components at single molecule level [31,32]. The method is based on detecting small shift in the peak value of the cantilever deflection signal that occur when a tip-tethered molecule (CBM) binds to a target (cellulose) on the surface, bridging the gap between the surface and an oscillating tip [32]. When combined with the single molecule dynamic force spectroscopy (SMDFS), this technique is capable of measuring unbinding forces and dynamic and kinetic parameters of the specific interactions between the molecules functionalized on the AFM tip and those immobilized on flat substrate, even on living cells [33,34]. The AFM recognition imaging is also used as a reliable and efficient tool in studying carbohydrate-protein interactions [35]. Recently, AFM recognition imaging and SMDFS have been applied to map the natural and pretreated poplar cell wall surface and study the affinity between a non-catalytic family 3 carbohydrate-binding module (CBM3a) and crystalline cellulose [36,37]. The crystalline cellulose exposed on cell wall surface was specifically recognized and its surface coverage was quantified [37].

In this study, we imaged the natural, dilute sulfuric acid pretreated and delignified plant cell wall surfaces of poplar, switchgrass, and corn stover by AFM recognition imaging. The AFM tip was functionalized by crystalline cellulosebinding CBM3a molecules (derived from Clostridium thermocellum Scaffoldin CipA). The surface structural changes of plant cell walls before and after pretreatments were measured and compared based on the recognition area percentage (RAP) of exposed crystalline cellulose.

\section{Results and discussion}

\section{Principles of AFM recognition imaging}

The crystalline cellulose distributions on natural and pretreated plant cell wall surfaces were specifically characterized by the well-established recognition imaging technique 
(Figure 1). The AFM tip was first coated with a magnetic material followed by a thin gold layer. The pre-coated tip was then functionalized by thiol- $\mathrm{PEG}_{2000}-\mathrm{NTA}-\mathrm{Ni}$ crosslinker in water and CBM3a molecules in Tris-Cl buffer [36]. The long and flexible $\mathrm{PEG}_{2000}$ was a commonly used crosslinker for minimizing the steric hindrance and misorientation [38,39]. Here, the active residues involved in crystalline cellulose binding are located at the "flat bottom" of the CBM3a molecule on the opposite side of the location of (His) ${ }_{6}$-tag, providing enough freedom for binding $[40,41]$. The gold-NTA-Ni-(His) ${ }_{6}$-tagged protein has been widely used as a stable chelating complex for specific binding [42].

Figure 1(a) shows a schematic of a modified AFM tip imaging the plant cell wall surface. When the crystalline cellulose is bound by CBM3a, the crosslinker will be stretched in the retraction process of the AFM cantilever. The top peak of the oscillations is reduced due to this energy loss and the specific interactions can be detected by generating a corresponding recognition signal. This process is followed by a further analysis in PicoTREC controller, which can split the raw deflection signal of the cantilever into the upper ( $U_{\max }$, marked in black) and lower ( $U_{\text {min }}$, marked in yellow) parts. These two parts of each circle are then recorded as the recognition and topography signals, respectively (Figure 1(b)) [41]. The pattern formed by several dark recognition patches clearly coincide with the positions of the crystalline cellulose in the topography image; meanwhile, the molecule on the substrate which doesn't have specific interactions with the modified AFM tip will not generate recognition signal, i.e., the green marks shown in the topography image in Figure 1(c). This recognition process has been widely used due to its great potential in molecular imaging of surfaces, while such measurements are very tedious and subject to errors and therefore great caution should be taken during sample preparation, data acquisition and interpretation [31,32]. For example, proper concentrations of CBM are critical to ensure single or just a few CBM molecules be modified on the AFM tip to avoid multi-molecular interactions.

\section{Surface mapping of natural plant cell walls of poplar, switchgrass, and corn stover}

Previously, we clearly visualized and recognized the crystalline cellulose on the surface of natural poplar slice. The recognition signal comes from the interaction between the CBM-functionalized AFM tip and the molecules on the sample surface. Therefore, to prove the specificity of the recognition, we measured the unbinding forces between the AFM tip (both CBM3a- functionalized and bare tip) and the poplar slice surface. The results indicated a pronounced, specific unbinding force peak in the force histograms for CBM3a-crystalline cellulose interaction, while near-zero, non-specific force was obtained when taking the force data for all the noncellulose areas on the poplar slice surface. For bare AFM tip, only the near-zero, non-specific force was observed for all the areas on the poplar slice surface [36,37]. In

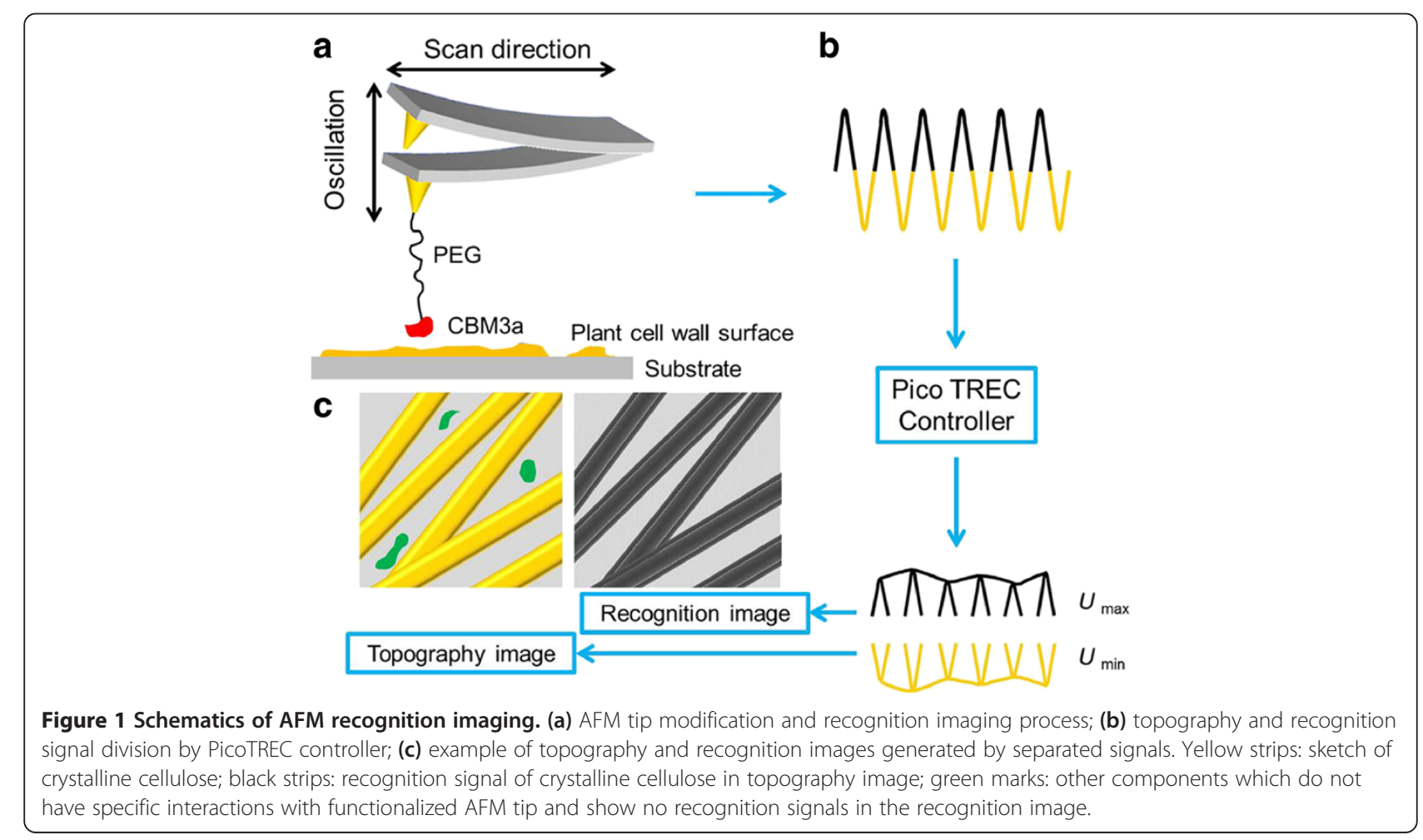




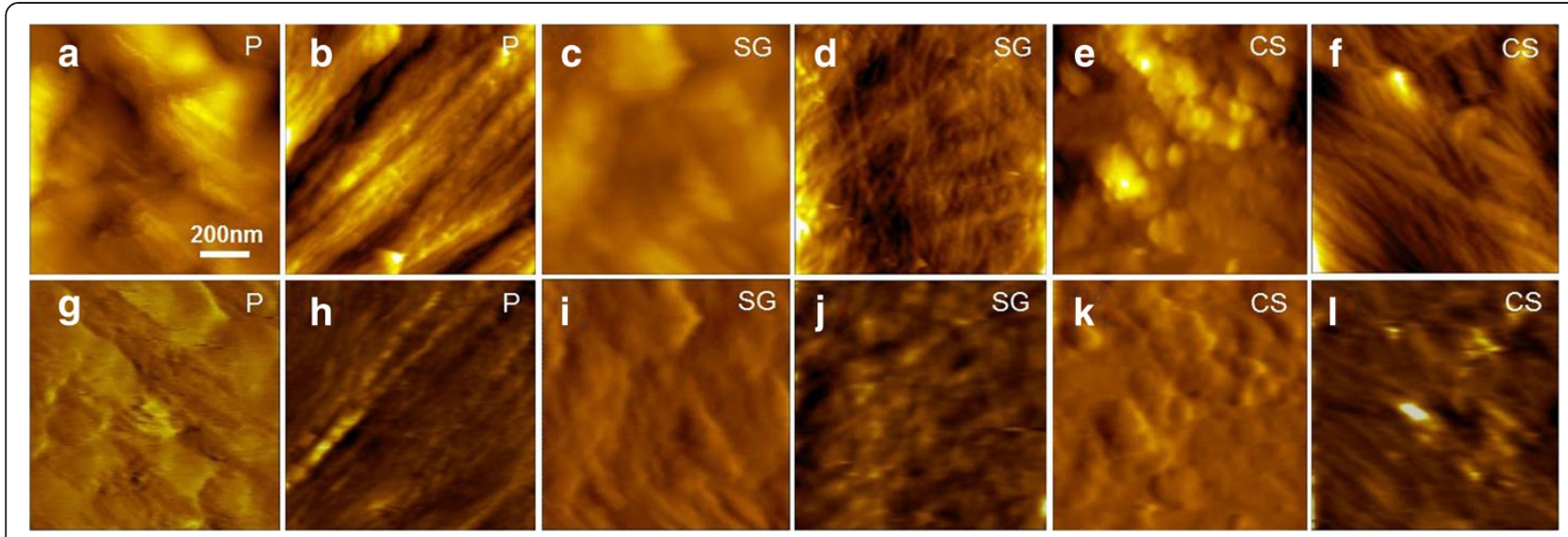

Figure 2 AFM topography and recognition images of natural plant cell walls. Topography (a-f) and recognition (g-l) images of natural poplar (P), switchgrass (SG), and corn stover (CS). (a, $\mathbf{c}, \mathbf{e}, \mathbf{g}, \mathbf{i}, \mathbf{k})$ show the representative surface area mainly covered by lignin and (b, $\mathbf{d}, \mathbf{f}, \mathbf{h}, \mathbf{j}, \mathbf{l})$ show the representative surface area mainly covered by crystalline cellulose.

this work, we also characterized the natural cell wall of switchgrass and corn stover and the representative topography and recognition images are shown in Figure 2.

It has been confirmed that the lignin content in poplar is about $10 \%$ higher than that in switchgrass and corn stover $[25,27]$. Accordingly, we observed more surface area covered by lignin or lignin-carbohydrate complex on the poplar plant cell wall than on switchgrass and corn stover. Besides, the morphology of poplar lignin exhibited smooth and intact layers while the lignin in switchgrass and corn stover formed irregular and compact granules as shown in the topography images of Figure 2(a), (c), and (e). Few surface components of these areas were recognized in the corresponding recognition images of Figure $2(\mathrm{~g})$, (i), and $(\mathrm{k})$, indicating the absence of specific interactions between non-cellulose components and CBM3a molecule on the AFM tip. Differently, on surface area extensively covered by parallel or interwoven crystalline cellulose microfibrils in Figure 2(b), (d), and (f), strong recognition signals were detected in the corresponding recognition images of Figure 2(h), (j), and (l).

\section{Measurement of recognition area percentage (RAP) on plant cell wall surfaces}

The crystalline cellulose distributions on the plant cell wall surface were quantitatively determined based on recognition signal distribution. For each biomass sample, 5 different surface areas in average were imaged on each single piece by the functionalized AFM tip. Over 20 sample pieces were imaged and 100 recognition images in size of $1 \mu \mathrm{m} \times 1 \mu \mathrm{m}$ were randomly selected for the RAP calculation. Generally, all the recognition images of each sample were divided into maximum 7 types based on the surface features represented by RAP of crystalline cellulose. Table 1 lists a summary of RAPs of each area type on pretreated and delignified corn stover cell wall surface (sample named as $0.5 \% \mathrm{CS}-135$ with $0.5 \%$ sulfuric acid concentration pretreated at $135^{\circ} \mathrm{C}$ ). The details of definition and calculation of area types are given in the Additional file 1: Section 2.

The representative topography and recognition images selected from each area type are shown in Figure 3. Based on surface components of pretreated cell wall before and after delignification, the majority of recognition images of $0.5 \%$ CS-135 were classified into type A through D, while most of the recognition images of delignified 0.5\%CS-135 showed the features of type E-G. The type A surface was mainly covered by irregularly shaped agglomerates with different sizes, which were mainly supposed to be the re-

Table 1 Recognition area percentage calculation of $0.5 \%$ CS-135 and delignified $0.5 \%$ CS-135 surface (100 images)

\begin{tabular}{lcccc}
\hline Sample ID & $\begin{array}{c}\text { Area } \\
\text { type }\end{array}$ & $\begin{array}{c}\text { Image } \\
\text { counts }\end{array}$ & $\begin{array}{c}\text { Average } \\
\text { RAP (\%) }\end{array}$ & $\begin{array}{c}\text { Total } \\
\text { RAP (\%) }\end{array}$ \\
\hline $0.5 \%$ CS -135 & A & 6 & 7.15 & 27.9 \\
& B & 19 & 17.0 & \\
& C & 25 & 24.7 & \\
& D & 28 & 34.9 & \\
& E & 9 & 44.8 & \\
$0.5 \%$ CS -135 delignified & F & 3 & 58.5 & \\
& G & 0 & - & 42.6 \\
& B & 0 & 0 & \\
& C & 0 & 0 & \\
& D & 21 & 34.5 & \\
& E & 36 & 43.1 & \\
& F & 25 & 52.4 & \\
& G & 6 & 59.5 & \\
\hline
\end{tabular}

Type A: < 10\%; B: 10-20\%; C: 20-30\%; D: 30-40\%; E: 40-50\%; F: 50-60; G: > 60\%. 


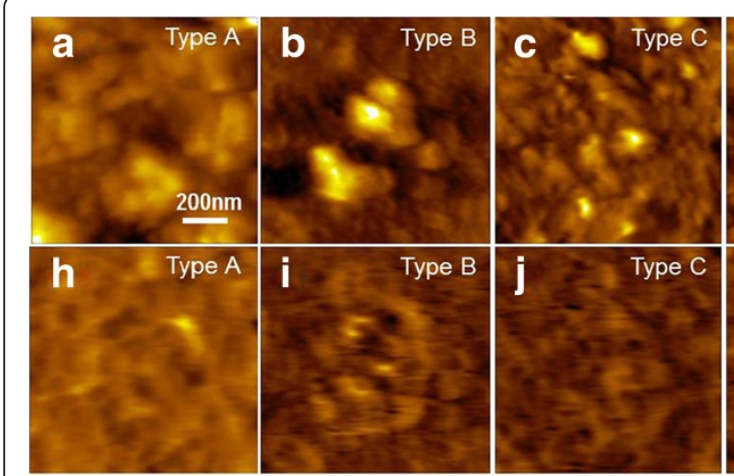

$0.5 \%$ CS -135
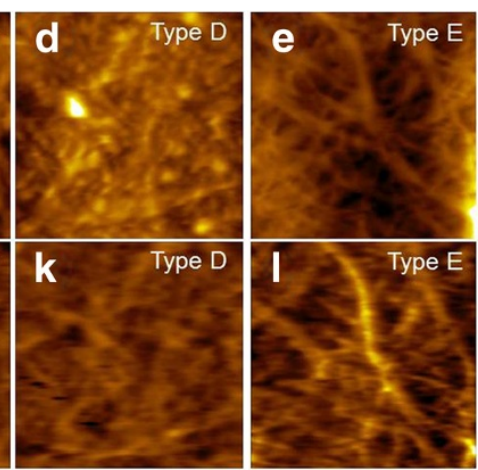

$0.5 \%$ CS-135 delignified
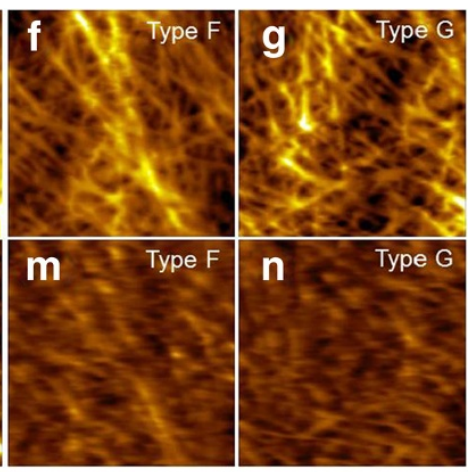

Figure 3 Representative topography and recognition images of $0.5 \%$ CS- 135 and delignified $0.5 \%$ CS- 135 surface of different area types. (a-g) topography images; (h-n) recognition images. $0.5 \% \mathrm{CS}-135$, corn stover cell wall pretreated by $0.5 \%$ sulfuric acid at $135^{\circ} \mathrm{C}$.

localized lignin after DAP [23]. The RAP of Figure 3(h) was lower than $10 \%$, indicating little CBM3a-cellulose interactions. From Type B to G, the amount and size of surface agglomerates gradually decreased and more crystalline cellulose appeared, resulting in an increase of RAPs to over $60 \%$. This difference denoted that the lignin locating on the surface of pretreated plant cell walls was extensively removed during the delignification process, therefore the crystalline cellulose underneath was exposed and recognized by the CBM3a-modified AFM tip [28].

\section{Effect of dilute acid pretreatment under different concentrations}

Hydrolysis of hemicellulose is considered as the main reaction occurring during acid pretreatment accompanied by fast condensation and precipitation of solubilized lignin as inevitable physical process [10,43]. The coalesced lignin deposits back onto the plant cell wall surfaces and potentially block further access to cell wall components as observed by SEM and AFM [23,44]. To quantitatively determine the component changes before and after DAP, we compared the surface of natural, dilute acid pretreated and delignified plant cell walls and calculated the RAPs. The plant cell wall surfaces were predominantly covered by lignin sheath, which was unevenly distributed all over the surface (Figure 4(a)). Recognition signals can hardly be seen due to the absence of specific CBM3acellulose interactions (Figure 4(e)). Remarkably, more crystalline cellulose microfibrils could be seen on the surface of $0.5 \%$ CS-135 sample in Figures 4(c) and (g) with higher RAPs than that of poplar $(0.5 \% \mathrm{P}-135)$ and switchgrass (0.5\%SG-135) (Additional file 1: Section 3.1). This result demonstrated that the cell wall of corn stover is more vulnerable to DAP process.

To determine the effect of DAP on cell wall surface structural changes other than lignin re-distribution, we removed the lignin by acidified sodium chlorite as shown in Figure 4(b, d, f and h). In Figure 4(b), the crystalline cellulose exhibited a compact configuration and individual crystalline cellulose microfibrils could hardly be distinguished. Some agglomerates could also be observed in Figure 4(d), which were supposed to be lignin residues (marked in red circles) that could not be recognized in Figure 4(h). The RAPs of natural and delignified corn stover were measured to be $15.2 \%$ and $29.4 \%$, respectively. The RAPs of natural corn stover and switchgrass (RAPs of natural switchgrass increased from 13.6\% to $26.1 \%$ after delignification) nearly doubled after delignification; meanwhile the RAPs of delignified poplar increased by $70 \%$ (RAPs of natural poplar increased from $12.9 \%$ to $21.8 \%$ after delignification) (Additional file 1 : Section 3.1 and 3.2). The less efficient delignification effect on poplar might due to a naturally higher content of intact lignin and a more solid cell wall structure. Comparatively, the surfaces of delignified cell walls after $0.5 \%$ sulfuric acid pretreatment at $135^{\circ} \mathrm{C}$ exhibit a more interrupted and interwoven configuration, especially for corn stover (Figure $4(\mathrm{~d})$ ) and switchgrass (Additional file 1: Section 3.2 Figure S3(d)). This morphology change was mainly caused by the removal of hemicellulose, therefore the linkage between crystalline cellulose was destroyed and individual crystalline cellulose microfibrils were released. The RAPs of $0.5 \%$ CS-135, 0.5\%SG-135 and 0.5\% P-135 were $27.9 \%, 20.4 \%$, and $17.4 \%$, respectively. After delignification, the RAPs of dilute acid pretreated corn stover and switchgrass increased by over $50 \%$ of their pretreated condition and that of pretreated poplar even doubled (Additional file 1: Section 3.2). The higher cellulose content in natural plant cell walls of poplar also contributed to a more substantial increase of RAP when more re-localized lignin droplets was removed (Additional file 1: Section 3.2 Figure S3(f)).

Various DAP conditions (e.g., altering temperature, acid concentration, reaction time, etc.) have been investigated to optimize the pretreatment results for better cell wall degradability [24]. The hemicellulose removal 

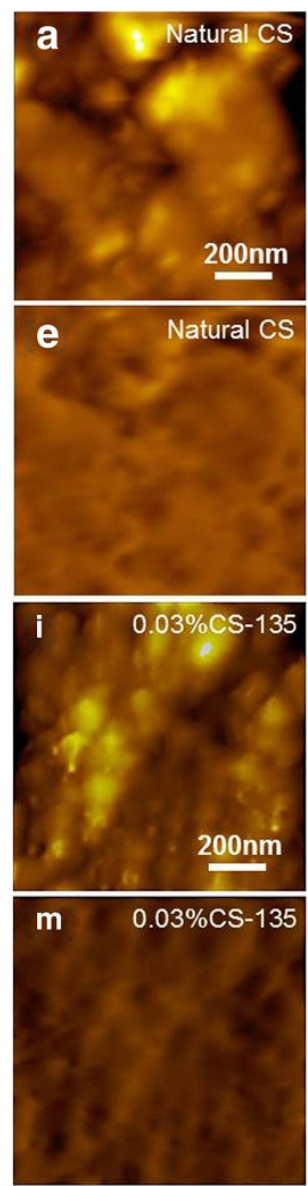
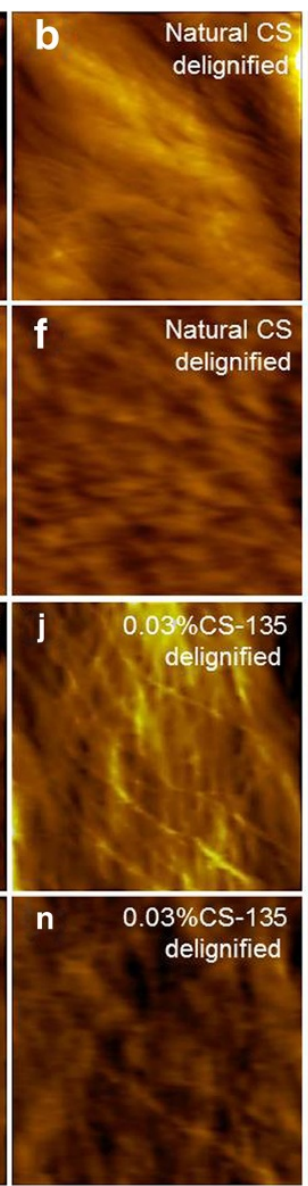
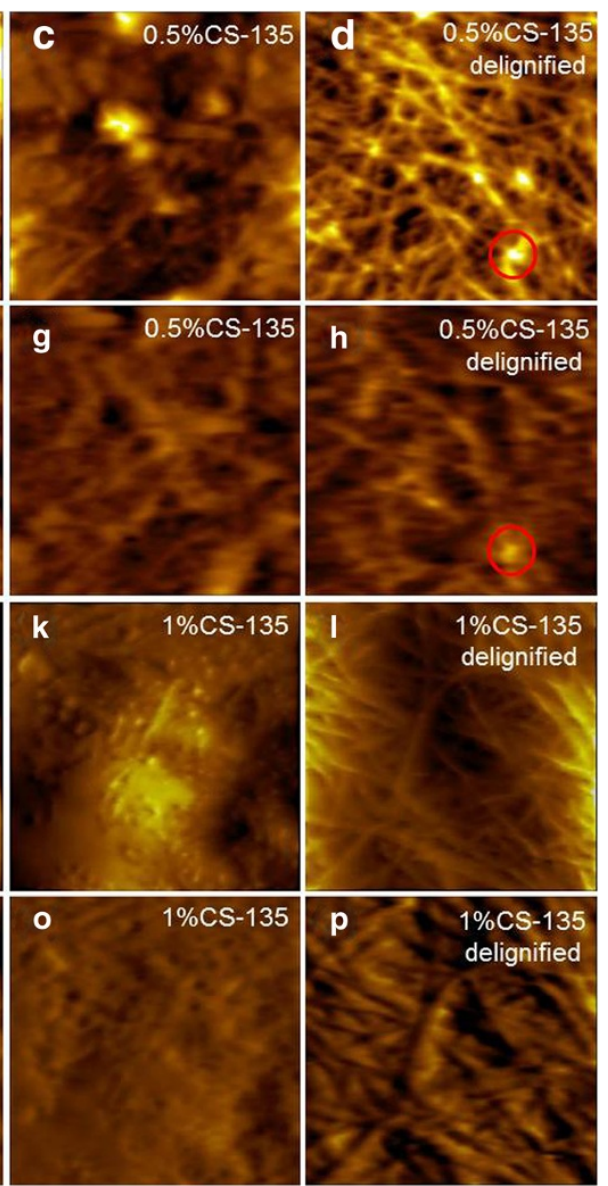

Figure 4 Topography and recognition images of natural, dilute acid pretreated, and delignified corn stover cell wall. Topography (a-d, i-l) and recognition (e-h, $\mathbf{m}-\mathbf{p}$ ) images of natural, dilute acid pretreated (pretreated by $0.03 \%, 0.5 \%$, and $1 \%$ sulfuric acid at $135^{\circ} \mathrm{C}$ ) and delignified corn stover cell wall. Some residues in (d) which do not have recognitions in (h) are highlighted in the red circles.

and re-localization of lignin are proven to be more pronounced with stronger acid or higher reaction temperature $[10,23]$. In the following work, we quantitatively studied the surface structural changes during DAP under different acid concentrations (i.e., 0.03\%, $0.5 \%, 1 \%$, and $2 \%$ ) as shown in Figure $4(\mathrm{i}-\mathrm{p})$. The surface structural changes after $0.03 \%$ and $1 \%$ DAP can be clearly seen in Figure 4(i and k). The size of agglomerates formed on the cell wall surfaces after $0.03 \%$ DAP was larger than that observed on surfaces pretreated by $1 \%$ acid, especially on $0.03 \% \mathrm{P}-135$ and $0.03 \%$ SG- 135 (Additional file 1: Section 3.3 Figure S4). The relocalized lignin was supposed to overlay the cell wall surfaces more evenly under high acid concentration and thereby to some extent, reduce the RAPs [23]. Some hemicellulose re-precipitated onto the cell wall surfaces under lower acid concentrations was also supposed to decrease the RAPs [22]. The same trend could also be observed on cell wall surfaces pretreated by $2 \%$ acid (Additional file 1: Section 3.5, Figure S6(a, c and e)).
To further understand the effect of acid concentrations on hemicellulose removal, we also removed the surface lignin to see the compositional changes underneath. In Figure $4(j)$, the exposed crystalline cellulose on $0.03 \%$ CS135 presented some interwoven arrangement, similar to the morphology observed on 0.03\%SG-135 (Additional file 1: Section 3.4 Figure S5(c)); while the exposed crystalline cellulose exhibits a more intact, parallel structure on $0.03 \%$ P-135 (Additional file 1: Section 3.4 Figure S5(a)). Moreover, less surface components were recognized on $0.03 \%$ P-135 (Additional file 1: Section 3.4 Figure S5(e)) than on 0.03\%SG-135 (Additional file 1: Section 3.4 Figure S4(g)) and $0.03 \% \mathrm{CS}-135$ in Figure 4(n). Therefore, the surface of delignified $0.03 \% \mathrm{P}-135$ was supposed to be covered by a large amount of hemicellulose, denoting a less effective removal of this component. When the cell walls of corn stover were previously pretreated with stronger acid, e.g., $1 \%$ or $2 \%$ acid, a denser, more regular crystalline cellulose structure were exposed after delignification (Figure 4(l)) and the corresponding recognition area also greatly 
increased (Figure 4(p)). The similar results were also observed on the delignified poplar and switchgrass (Additional file 1: Section 3.4 Figure S5(b and d)). The images of cell walls pretreated by $2 \%$ sulfuric acid at $135^{\circ} \mathrm{C}$ are shown and discussed in Additional file 1: Section 3.5 Figure S6.

Similarly, the RAPs of $0.03 \%$ CS- 135 and $1 \%$ CS- 135 were determined to be $19.4 \%$ and $15.9 \%$, respectively. The RAPs of $0.03 \% \mathrm{P}-135$ and $0.03 \% \mathrm{SG}-135$ also decreased from $14.8 \%$ to $13.5 \%$ and $17.3 \%$ to $15.2 \%$, respectively when compared with $1 \% \mathrm{P}-135$ and $1 \%$ SG-135. The results demonstrated that the RAPs decreased with a higher acid concentration which caused more extensive and even lignin coverage by smaller lignin droplets and corn stover exhibited better accessibility. After delignification, the RAP of $0.03 \%$ CS- 135 was $35.3 \%$ and the RAP of $1 \%$ CS- 135 became $50.8 \%$. The RAPs of delignified poplar and switchgrass also showed the same trend, i.e., the RAPs of poplar increased from $29.4 \%(0.03 \% \mathrm{P}-135)$ to $41.2 \%$ (1\%P-135), while the RAPs of switchgrass increased from $31.1 \%$ (0.03\%SG-135) to $43.8 \%$ (1\%SG-135) (Additional file 1: Section 3.4). Hence, compared with $0.03 \%$ acid, cell wall pretreatment with $1 \%$ acid exhibited 6-12\% more surface accessibility of crystalline cellulose by dissolving more hemicellulose, although the surface lignin was hardly removed. Notably, the polymerization of the crystalline cellulose was also affected under the high acid concentration by inducing the decrease of microfibril length as shown in Figure $4(\mathrm{~d}$ and $\mathrm{l})$, therefore more reducing-ends were supposed to be produced (Additional file 1: Section 3.3 and 3.4).

To sum up, the dilute acid pretreatment effectively dissolve hemicellulose but showed no pronounced removal of lignin, at least on the outer surface of plant cell wall. The plant cell wall was also deconstructed due to removal of hemicellulose and lignin after delignification. The corn stover cell wall showed less recalcitrance compared to poplar and switchgrass.

\section{Area type distributions and RAP summary of natural and pretreated plant cell walls}

As an average value, however, RAP cannot tell the differences of surface conditions before and after pretreatments. For instance, the RAP of natural corn stover is $15.2 \%$, which is very close to the RAPs of $1 \%$ CS -135 (15.9\%) and 2\%CS-135 (16.2\%). However, it doesn't necessarily mean that the surface component distributions are the same. To explore the changes of plant cell wall structures, the number of recognition images in each area type was counted and the results were compiled in Figure 5.

The distributions in Figure 5(a) clearly manifested that for natural corn stover, more than half of the surface structures were defined as type A and B and about one fourth of the recognitions images showed the features of
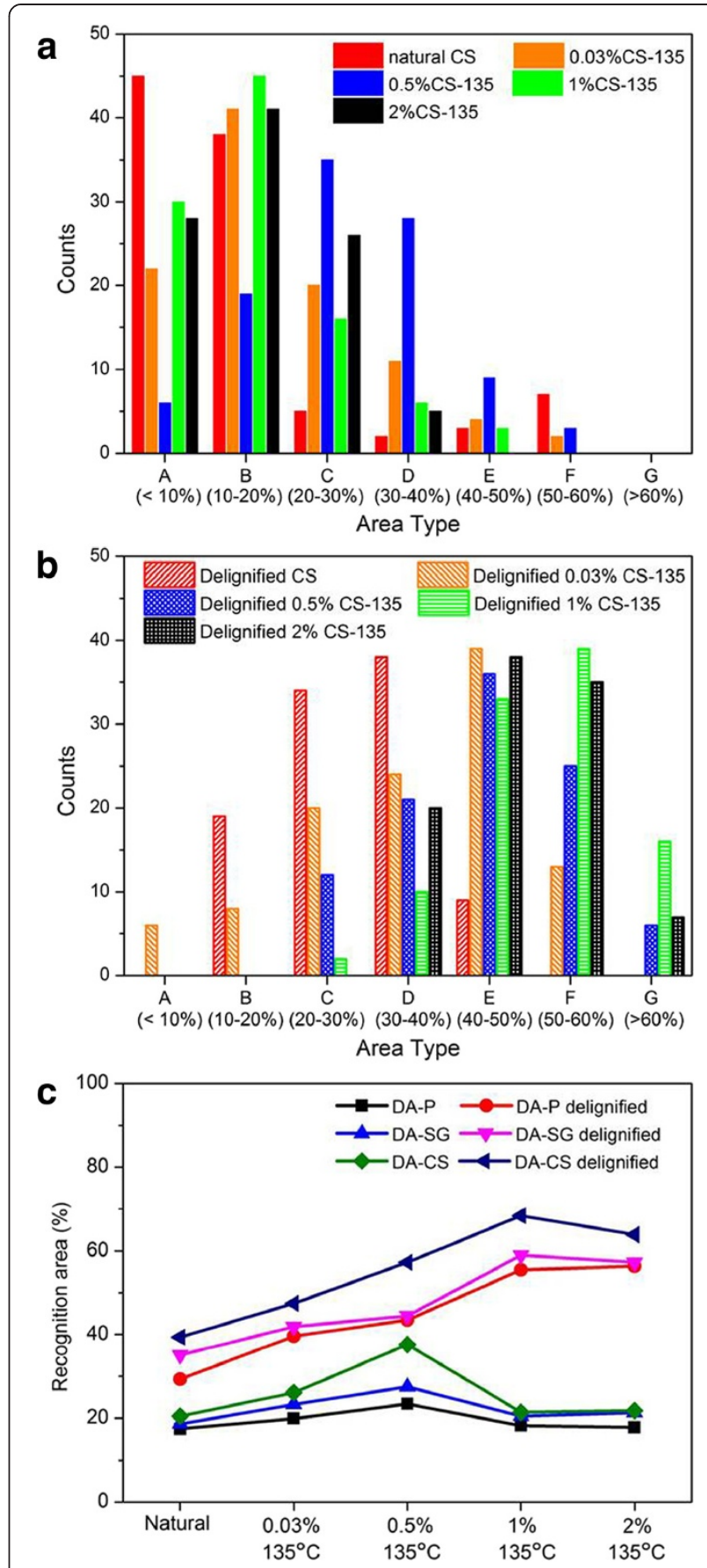

Figure 5 Area type distributions and recognition are percentage summary. (a) Area type distributions of natural and dilute acid pretreated cell wall surfaces of corn stover; (b) Area type distributions of delignified cell wall surfaces of corn stover; (c) Recognition area percentage (RAP) summary of natural and pretreated poplar, switchgrass, and corn stover cell wall surfaces.

type $\mathrm{E}$ and $\mathrm{F}$. The crystalline cellulose in natural plant cell walls were highly ordered, lacking the favorable position for specific CBM binding, therefore the recognized area was quite limited and the RAP cannot reach to over 
$60 \%$ as defined in type G. After DAP, over $60 \%$ of surface features were grouped in type $\mathrm{B}$ and $\mathrm{C}$, indicating a slight interruption of lignin coverage and higher crystalline cellulose accessibility. Remarkably, for $0.5 \%$ CS-135, the majority of recognition images located in type $C$ and $\mathrm{D}$, which also gave a much higher RAP value and exhibited a more evenly distributed crystalline cellulose.

After removal of lignin, the image distributions changed evidently as shown in Figure 5(b). The area types distributed more widely and more surface features were determined as type D through G. For delignified corn stover without DAP, more than half of the images areas revealed features of type $C$ and $D$, whereas the majority of surface features of $0.03 \% \mathrm{CS}-135,1 \% \mathrm{CS}-135$, and $2 \% \mathrm{CS}-135$ were determined as type D through $\mathrm{F}$. Some areas classified as type G, especially on $2 \%$ CS -135 , validated a more effective removal of hemicellulose under higher acid concentration. Similar results could also be obtained on poplar and switchgrass as shown in Additional file 1: Section 4.

Due to the limitation of high scan speed during imaging, surface roughness and unfavorable position of crystalline cellulose for binding, the recognition efficiency and accuracy were supposed to have their own limitations $[32,45]$. Therefore, to reflect more accurate surface crystalline cellulose distributions, we used Avicel as a control to calibrate the RAPs. The RAP of Avicel, a commercial product containing up to $97 \%$ of microcrystalline cellulose, was measured to be $72.1 \%$ (Additional file 1: data Section 5). Hence the recognition efficiency was simply defined as $72.1 \%$ / 97\% $=74.3 \%$. After calibration, we summarized the new RAPs obtained under different acid concentrations at $135^{\circ} \mathrm{C}$ into Figure $5(\mathrm{c})$.

Figure 5(c) illustrates a direct view of RAPs measured on all biomass species under different pretreatment conditions. After DAP, the RAPs of poplar, switchgrass, and corn stover increased slightly and reached a highest value when the acid concentration was $0.5 \%$ and then decreased. At the acid concentration higher than 1\%, the surface structure was supposed to have less correlation to the acid concentration and no further improvement of RAPs was observed. With $0.5 \%$ DAP, the cell wall deconstruction, hemicellulose removal, and lignin reprecipitation reached to a balance point so that the crystalline cellulose skeleton was exposed to a maximum level with the highest RAP. After delignification, however, the RAPs could be correlated to acid concentration up to $2 \%$. When the surface lignin droplets were nearly completely removed, the blocking effect was greatly eliminated and the cell walls pretreated under higher acid concentrations presented more interrupted structures with more binding-favorable positions of crystalline cellulose. A slight decrease of RAPs in switchgrass and corn stover pretreated by $2 \%$ acid could be attributed to a more evident effect of depolymerization of crystalline cellulose, lower surface density of surface crystalline cellulose microfibrils due to extensive removal of hemicellulose or partial generation and deposition of pseudo-lignin [46,47].

In summary, the RAPs after calibration indicated that the increasing acid concentration caused more effective removal of hemicellulose on all plant cell wall surfaces; meanwhile the surface coverage of re-precipitated lignin droplets reduced slightly and then intensified with highest RAP at $0.5 \%$ acid. The surface chemical components changes were further qualitatively determined by grazing angle attenuated total reflectance Fourier transform infrared (ATR-FTIR) spectroscopy. The spectra (poplar, as an example) indicated a conclusion similar to RAP results (Additional file 1: Section 6, Figure S9).

\section{Effect of dilute acid pretreatment under different temperatures}

DAP under high temperatures $\left(130^{\circ} \mathrm{C}-220^{\circ} \mathrm{C}\right)$ was considered to highly improve plant cell wall deconstruction [23]. According to Moxley et al. [22], cellulose accessibility was closely correlated to hemicellulose solubilization at lower pretreatment temperatures; at higher temperatures, however, lignin degradation has a better correlation with cellulose accessibility. Here we compared the surface structural changes of corn stover and switchgrass cell walls pretreated by $0.5 \%$ acid at $135^{\circ} \mathrm{C}$ and $160^{\circ} \mathrm{C}$. Figure $6(\mathrm{a}, \mathrm{c})$ reveal re-deposited lignin droplets on the cell wall surfaces. Notably, the droplet on surfaces of $0.5 \%$ CS-135 was slightly larger than that on surfaces of $0.5 \% \mathrm{CS}-160$. This difference could be attributed to depolymerization and translocation of lignin under higher pretreatment temperature [23].

After delignification, the deconstructed cell wall surfaces were fully exposed with features of parallel and interwoven crystalline cellulose. As shown in Figure 6(b and d) and Additional file 1: Section 6 (Figure S9), the crystalline cellulose microfibrils on surfaces of $0.5 \% \mathrm{CS}-160$ and $0.5 \%$ SG-160 were better separated than those on surfaces of $0.5 \%$ CS-135 and $0.5 \%$ SG-135, depicting a more in-depth and delicate removal of hemicellulose among individual cellulose microfibrils. The recognition signals in Figure 6(h) also showed more delicate distribution compared with that in Figure 6(f). On the other hand, 0.5\%SG-135 and $0.5 \%$ CS- 135 showed the RAPs of $27.5 \%$ and $37.6 \%$, respectively (after calibration, the same for the following RAPs). These values were slightly lower than the RAPs of 0.5\%SG-160 (28.5\%) and 0.5\%CS-160 (39.9\%). Corn stover cell walls again seemed to be more sensitive to higher temperature. Accordingly, the RAPs of delignified $0.5 \%$ SG-135 and $0.5 \%$ CS- 135 were measured to be $44.5 \%$ and $57.3 \%$, respectively, lower than the RAPs of $0.5 \%$ SG- 160 (47.8\%) and $0.5 \% \mathrm{CS}-160$ (61.1\%) respectively. Therefore, 

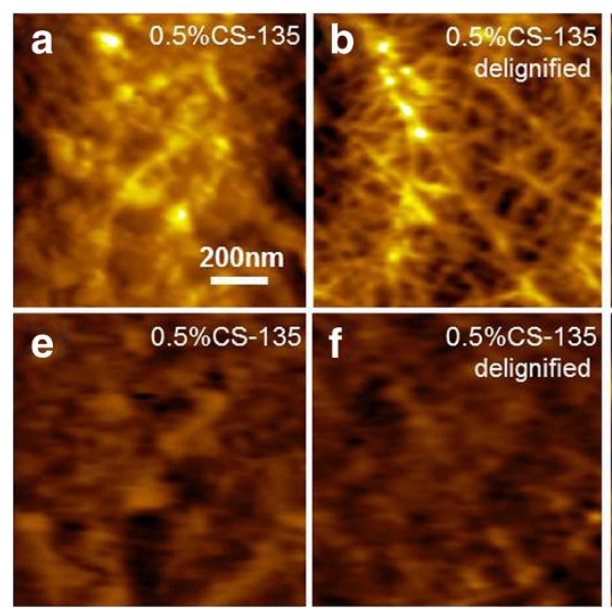
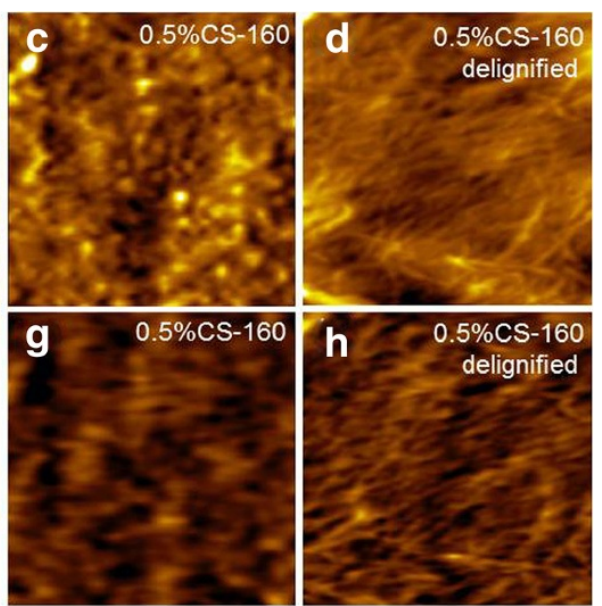

Figure 6 Topography and recognition images of dilute acid pretreated $\left(135^{\circ} \mathrm{C}\right.$ and $\left.160^{\circ} \mathrm{C}\right)$ and delignified corn stover cell wall. (a-d) Topography images; (e-h) Recognition images. 0.5\%CS-135, corn stover cell wall pretreated by $0.5 \%$ sulfuric acid at $135^{\circ} \mathrm{C} ; 0.5 \%$ CS-160, corn stover cell wall pretreated by $0.5 \%$ sulfuric acid at $160^{\circ} \mathrm{C}$.

DAP under higher temperature revealed a higher efficiency in plant cell wall deconstruction, especially for corn stover.

\section{Conclusions}

Based on AFM recognition imaging and area percentage calculations, our results showed that $17-20 \%$ of plant cell wall surfaces were covered by crystalline cellulose before pretreatment and this coverage increased to $23-38 \%$ after dilute acid pretreatment under different temperature and acid concentrations. When the plant cell walls were pretreated with $0.5 \%$ sulfuric acid, the crystalline cellulose surface distribution of $23 \%$ on poplar, $28 \%$ on switchgrass, and $38 \%$ on corn stover was determined as an optimized result at $135^{\circ} \mathrm{C}$. Compared to bulk component analysis, this method exhibits pronounced advantages in providing detailed surface information of plant cell walls.

\section{Methods}

\section{Preparation of recombinant CBM3a and AFM tip} functionalization

The recombinant CBM3a was provided by Complex Carbohydrate Research Center, University of Georgia. The AFM tips used (CS-10 silicon) were purchased from Nanoscience Instruments, Phoenix, AZ with the nominal spring constant of $0.1 \mathrm{~N} / \mathrm{m}$. The preparation method of recombinant CBM3a and the CBM3a-AFM tip functionalization procedure have been described in details elsewhere [36].

\section{Dilute sulfuric acid pretreatment of biomass samples} All biomass for pretreatment were ball-milled (8000 M Mixer/Mill, SPEX SamplePrep, Metuchen NJ) and sieved by mesh screen. The sample pieces in size of $200-250 \mu \mathrm{m}$ were collected, washed by DI water, and dried at $45^{\circ} \mathrm{C}$ for $24 \mathrm{~h} .0 .1 \mathrm{~g}$ ball-milled biomass of each species was pre-soaked in dilute sulfuric acid $(0.03 \% \mathrm{w} / \mathrm{w}, 2 \mathrm{~mL})$ (VWR, Radnor, PA) for $30 \mathrm{~min}$ in a $20 \mathrm{~mL}$ glass pressure tube (Ace Glass Incorporated, Vineland, NJ). The sealed pressure tube was heated in a heating block on a hot plate (Barnstead/Thermolyne - RT Elite, Dubuque, IA) at $135^{\circ} \mathrm{C}$ for $20 \mathrm{~min}$. The reaction was stopped by cooling down the tube to room temperature in cold DI water. The pretreated sample was then washed by $10 \mathrm{~mL}$ DI water for 5 times and centrifuged with $1 \mathrm{~mL}$ DI water (5,000 rpm, $10 \mathrm{~min}$ ) for 5 times (SORVALL BioFuge Pico Microcentrifuge, Thermo Electron Corporation, Waltham, $\mathrm{MA}$ ) and finally dried in air at $45^{\circ} \mathrm{C}$ for $24 \mathrm{~h}$. The same procedure was repeated at $135^{\circ} \mathrm{C}$ for all three species with $0.5 \% \mathrm{w} / \mathrm{w}, 1 \% \mathrm{w} / \mathrm{w}$, and $2 \% \mathrm{w} / \mathrm{w}$ sulfuric acid. The switchgrass and corn stover pretreated in $0.5 \% \mathrm{w} / \mathrm{w}$ sulfuric acid at $160^{\circ} \mathrm{C}\left(0.095 \mathrm{~g} \mathrm{H}_{2} \mathrm{SO}_{4}\right.$ : dry wt, $5 \mathrm{wt}$ \% solids $)$ were provided by the University of California at Riverside. The summary of all pretreatment conditions and sample nominations are compiled in Table 1 in the Additional file 1: Section 1.

\section{Delignification of dilute acid pretreated biomass samples}

The pretreated samples were subsequently delignified following one of the leading methods [28]. Briefly, $0.02 \mathrm{~g}$ sodium chlorite (J. T. Baker, Phillipsburg, NJ) and $40 \mu \mathrm{L}$ glacial acetic acid (VWR, Radnor, PA) was added into each pretreated biomass water slurry ( $3 \%$ solid, $1 \mathrm{~mL}$ ). The reaction was taken at $80^{\circ} \mathrm{C}$ for $1.5 \mathrm{~h}$ with gentle stirring. After cooling down, the bleached sample was washed 8 times with DI water followed by centrifugation at $10,000 \mathrm{rpm}$ for $10 \mathrm{~min}$ and then was dried in air at $45^{\circ} \mathrm{C}$ for $24 \mathrm{~h}$. 


\section{AFM sample preparation and experimental setup for recognition imaging}

The AFM sample preparation procedure was the same as poplar slice immobilization as described in our previous paper [36]. The PicoPlus Molecular Imaging system together with a PicoScan 3000 Controller was used in this work. An Agilent multipurpose AFM scanner with open loop was used for all recognition imaging. All images were taken using non-contact, top magnetic AC (TopMAC) mode under PicoTREC (Agilent Technologies, Santa Clara, CA). The topography (height) and recognition images were conducted simultaneously [32,37]. The 200-500 $\mu \mathrm{m}$ handcut, natural pieces of each biomass sample after mesh screening (200-500 $\mu \mathrm{m}$ in size) before pretreatments and pure microcrystalline cellulose Avicel PH-105 (FMC BioPolymer, Philadelphia, PA, nominal particle size: $20 \mu \mathrm{m})$ were also imaged. For each sample, about 20 pieces were randomly imaged by the functionalized AFM tip at an average scanning speed of $6 \mu \mathrm{m} / \mathrm{s} .100$ recognition images in size of $1 \mu \mathrm{m} \times 1 \mu \mathrm{m}$ were randomly selected for the recognition area percentage calculation.

\section{Additional file}

Additional file 1: Supporting figures and tables.

\section{Abbreviations}

AFM: Atomic force microscopy; P: Poplar; SG: Switchgrass; CS: Corn stover; CBM: Carbohydrate-binding module; DAP: Dilute acid pretreatment; RAP: Recognition area percentage.

\section{Competing interests}

The authors declare that they have no competing interests.

\section{Authors' contributions}

BX conceived of the study. MZ performed the experiment and analyzed the data. GC designed the schemes of AFM tip chemical functionalization. RK generated the plant materials. MZ and BX drafted the manuscript. All authors read and approved the final manuscript.

\section{Acknowledgements \\ We thank Dr. Sheng-cheng Wu from Complex Carbohydrate Research Center, University of Georgia for providing the CBM molecules. We also thank Dr. Jim Kastner from College of Engineering, University of Georgia for providing pretreatment facilities, and Dr. Sudhagar Mani from College of Engineering, University of Georgia for providing ball mill and natural switchgrass sample. We also thank Dr. Jason Locklin from Department of Chemistry, University of Georgia for providing ATR-FTIR equipment. The research was supported by National Science Foundation (CBET 1139057, ECCS 1231967).}

\section{Author details \\ ${ }^{1}$ Single Molecule Study Laboratory, College of Engineering and Nanoscale Science and Engineering Center, University of Georgia, Athens, GA 30602, USA. ${ }^{2}$ Present address: Bruker Nano Surface Division, 112 Robin Hill Road, Santa Barbara, CA 93117, USA. ${ }^{3}$ Center for Environmental Research and Technology, Bourns College of Engineering, University of California, Riverside, 1084 Columbia Avenue, Riverside, CA 92507, USA.}

Received: 16 July 2013 Accepted: 7 October 2013

Published: 11 October 2013

\section{References}

1. Jordan DB, Bowman MJ, Braker JD, Dien BS, Hector RE, Lee CC, Mertens JA, Wagschal K: Plant cell walls to ethanol. Biochem J 2012, 442:241-252.

2. Solomon BD: Biofuels and sustainability. Ecol Econ Rev 2010, 1185:119-134.

3. Chundawat SPS, Beckham GT, Himmel ME, Dale BE: Deconstruction of lignocellulosic biomass to fuels and chemicals. Annu Rev Chem Biomol Eng 2011, 2:121-145.

4. Zaldivar J, Nielsen J, Olsson L: Fuel ethanol production from lignocellulose: a challenge for metabolic engineering and process integration. Appl Microbiol Biot 2001, 56:17-34

5. Martinez AT, Speranza M, Ruiz-Duenas FJ, Ferreira P, Camarero S, Guillen F, Martinez MJ, Gutierrez A, del Rio JC: Biodegradation of lignocellulosics: microbial, chemical, and enzymatic aspects of the fungal attack of lignin. Int Microbiol 2005, 8:195-204.

6. Himmel ME, Ding SY, Johnson DK, Adney WS, Nimlos MR, Brady JW, Foust TD: Biomass recalcitrance: engineering plants and enzymes for biofuels production. Science 2007, 315:804-807.

7. Somerville C, Bauer S, Brininstool G, Facette M, Hamann T, Milne J, Osborne E, Paredez A, Persson S, Raab T, Vorwerk S, Youngs H: Toward a systems approach to understanding plant cell walls. Science 2004, 306:2206-2211.

8. Ding SY, Liu YS, Zeng YN, Himmel ME, Baker JO, Bayer EA: How does plant cell wall nanoscale architecture correlate with enzymatic digestibility? Science 2012, 338:1055-1060.

9. Cosgrove DJ, Jarvis MC: Comparative structure and biomechanics of plant primary and secondary cell walls. Front Plant Sci 2012, 3:204.

10. Zhao XB, Zhang LH, Liu DH: Biomass recalcitrance. Part II: fundamentals of different pre-treatments to increase the enzymatic digestibility of lignocellulose. Biofuels Bioprod Biorefin 2012, 6:561-579.

11. Yang B, Wyman CE: Pretreatment: the key to unlocking low-cost cellulosic ethanol. Biofuels Bioprod Biorefin 2008, 2:26-40

12. Jeoh T, Ishizawa Cl, Davis MF, Himmel ME, Adney WS, Johnson DK Cellulase digestibility of pretreated biomass is limited by cellulose accessibility. Biotechnol Bioeng 2007, 98:112-122.

13. Lau MW, Gunawan C, Dale BE: The impacts of pretreatment on the fermentability of pretreated lignocellulosic biomass: a comparative evaluation between ammonia fiber expansion and dilute acid pretreatment. Biotechnol Biofuels 2009, 2:30.

14. Li JB, Henriksson G, Gellerstedt G: Lignin depolymerization/ repolymerization and its critical role for delignification of aspen wood by steam explosion. Bioresour Technol 2007, 98:3061-3068.

15. Bals B, Rogers C, Jin MJ, Balan V, Dale BE: Evaluation of ammonia fibre expansion (AFEX) pretreatment for enzymatic hydrolysis of switchgrass harvested in different seasons and locations. Biotechnol Biofuels 2010, 3:1.

16. Kim TH, Lee YY: Pretreatment and fractionation of corn stover by ammonia recycle percolation process. Bioresour Technol 2005, 96:2007-2013.

17. Kaar WE, Holtzapple MT: Using lime pretreatment to facilitate the enzymic hydrolysis of corn stover. Biomass Bioenergy 2000, 18:189-199.

18. Foston M, Ragauskas AJ: Changes in lignocellulosic supramolecular and ultrastructure during dilute acid pretreatment of Populus and switchgrass. Biomass Bioenergy 2010, 34:1885-1895.

19. Baboukani BS, Vossoughi M, Alemzadeh I: Optimisation of dilute-acid pretreatment conditions for enhancement sugar recovery and enzymatic hydrolysis of wheat straw. Biosyst Eng 2012, 111:166-174.

20. Bondesson PM, Galbe M, Zacchi G: Ethanol and biogas production after steam pretreatment of corn stover with or without the addition of sulphuric acid. Biotechnol Biofuels 2013, 6:11

21. Ishizawa Cl, Jeoh T, Adney WS, Himmel ME, Johnson DK, Davis MF: Can delignification decrease cellulose digestibility in acid pretreated corn stover? Cellulose 2009, 16:677-686.

22. Moxley G, Gaspar AR, Higgins D, Xu H: Structural changes of corn stover lignin during acid pretreatment. J Ind Microbiol Biot 2012. 39:1289-1299.

23. Selig MJ, Viamajala S, Decker SR, Tucker MP, Himmel ME, Vinzant TB: Deposition of lignin droplets produced during dilute acid pretreatment of maize stems retards enzymatic hydrolysis of cellulose. Biotechnol Progr 2007, 23:1333-1339. 
24. Chen Y, Stevens MA, Zhu YM, Holmes J, Moxley G, Xu H: Reducing acid in dilute acid pretreatment and the impact on enzymatic saccharification. $J$ Ind Microbiol Biot 2012, 39:691-700.

25. Kumar R, Mago G, Balan V, Wyman CE: Physical and chemical characterizations of corn stover and poplar solids resulting from leading pretreatment technologies. Bioresour Technol 2009, 100:3948-3962.

26. Chundawat SPS, Donohoe BS, Sousa LD, Elder T, Agarwal UP, Lu FC, Ralph J, Himmel ME, Balan V, Dale BE: Multi-scale visualization and characterization of lignocellulosic plant cell wall deconstruction during thermochemical pretreatment. Energy Environ Sci 2011, 4:973-984.

27. Donohoe BS, Vinzant TB, Elander RT, Pallapolu VR, Lee YY, Garlock RJ, Balan V, Dale BE, Kim Y, Mosier NS, Ladisch MR, Falls M, Holtzapple MT, Sierra-Ramirez R, Shi J, Ebrik MA, Redmond T, Yang B, Wyman CE, Hames B, Thomas S, Warner RE: Surface and ultrastructural characterization of raw and pretreated switchgrass. Bioresour Technol 2011, 102:11097-11104.

28. Kristensen JB, Thygesen LG, Felby C, Jorgensen H, Elder T: Cell-wall structural changes in wheat straw pretreated for bioethanol production. Biotechnol Biofuels 2008, 1:5.

29. Kawakubo T, Karita S, Araki Y, Watanabe S, Oyadomari M, Takada R, Tanaka F, Abe K, Watanabe T, Honda Y, Watanabe T: Analysis of exposed cellulose surfaces in pretreated wood biomass using carbohydrate-binding module (CBM)-cyan fluorescent protein (CFP). Biotechnol Bioeng 2010, 105:499-508.

30. Jung S, Foston M, Sullards MC, Ragauskas AJ: Surface characterization of dilute acid pretreated populus deltoides by ToF-SIMS. Energy Fuels 2010, 24:1347-1357.

31. Hinterdorfer P, Dufrene YF: Detection and localization of single molecular recognition events using atomic force microscopy. Nat Methods 2006, 3:347-355.

32. Stroh C, Wang HD, Bash R, Ashcroft B, Nelson J, Gruber H, Lohr D, Lindsay SM, Hinterdorfer P: Single-molecule recognition imaging microscopy. Proc Natl Acad Sci USA 2004, 101:12503-12507.

33. Lee S, Mandic J, Van Vliet KJ: Chemomechanical mapping of ligand-receptor binding kinetics on cells. Proc Natl Acad Sci USA 2007, 104:9609-9614.

34. Lee CK, Wang YM, Huang LS, Lin SM: Atomic force microscopy: determination of unbinding force, off rate and energy barrier for protein-ligand interaction. Micron 2007, 38:446-461.

35. Zhao WD, Liu SH, Cai MJ, Xu HJ, Jiang JG, Wang HD: Detection of carbohydrates on the surface of cancer and normal cells by topography and recognition imaging. Chem Commun 2013, 49:2980-2982.

36. Zhang MM, Wu SC, Zhou W, Xu BQ: Imaging and measuring singlemolecule interaction between a carbohydrate-binding module and natural plant cell wall cellulose. J Phys Chem B 2012, 116:9949-9956.

37. Zhang MM, Wang B, Xu BQ: Measurements of single molecular affinity interactions between carbohydrate-binding modules and crystalline cellulose fibrils. Phys Chem Chem Phys 2013, 15:6508-6515.

38. Chen GJ, Zhou JF, Park B, Xu BQ: Single ricin detection by atomic force microscopy chemomechanical mapping. Appl Phys Lett 2009, 95:043103.

39. Hinterdorfer P, Baumgartner W, Gruber HJ, Schilcher K, Schindler H: Detection and localization of individual antibody-antigen recognition events by atomic force microscopy. Proc Natl Acad Sci USA 1996, 93:3477-3481.

40. Tormo J, Lamed R, Chirino AJ, Morag E, Bayer EA, Shoham Y, Steitz TA: Crystal structure of a bacterial family-III cellulose-binding domain: a general mechanism for attachment to cellulose. Embo J 1996, 15:5739-5751.

41. Ebner A, Kienberger F, Kada G, Stroh CM, Geretschlager M, Kamruzzahan ASM, Wildling L, Johnson WT, Ashcroft B, Nelson J, Lindsay SM, Gruber HJ, Hinterdorfer P: Localization of single avidin-biotin interactions using simultaneous topography and molecular recognition imaging. ChemPhysChem 2005, 6:897-900.

42. Hainfeld JF, Liu W, Halsey CM, Freimuth P, Powell RD: Ni-NTA-gold clusters target His-tagged proteins. J Struct Biol 1999, 127:185-198.

43. Liu CG, Wyman CE: The effect of flow rate of compressed hot water on xylan, lignin, and total mass removal from corn stover. Ind Eng Chem Res 2003, 42:5409-5416.

44. Hansen MAT, Kristensen JB, Felby C, Jorgensen H: Pretreatment and enzymatic hydrolysis of wheat straw (Triticum aestivum L.) - The impact of lignin relocation and plant tissues on enzymatic accessibility. Bioresour Technol 2011, 102:2804-2811.

45. Wang B, Guo CL, Zhang MM, Park B, Xu BQ: High-resolution single-molecule recognition imaging of the molecular details of ricin-aptamer interaction. J Phys Chem B 2012, 116:5316-5322.

46. Kumar R, Hu F, Sannigrahi P, Jung S, Ragauskas AJ, Wyman CE: Carbohydrate derived-pseudo-lignin can retard cellulose biological conversion. Biotechnol Bioeng 2013, 110:737-753.

47. Sannigrahi $P$, Kim DH, Jung S, Ragauskas A: Pseudo-lignin and pretreatment chemistry. Energy Environ Sci 2011, 4:1306-1310.

doi:10.1186/1754-6834-6-147

Cite this article as: Zhang et al:: Mapping out the structural changes of natural and pretreated plant cell wall surfaces by atomic force microscopy single molecular recognition imaging. Biotechnology for Biofuels 2013 6:147.

\section{Submit your next manuscript to BioMed Central and take full advantage of:}

- Convenient online submission

- Thorough peer review

- No space constraints or color figure charges

- Immediate publication on acceptance

- Inclusion in PubMed, CAS, Scopus and Google Scholar

- Research which is freely available for redistribution 